\title{
Stroke Happens Suddenly so It Cannot Be Prevented: A Qualitative Study to Understand Knowledge, Attitudes, and Practices about Stroke in Rural Gadchiroli, Maharashtra, India
}

\author{
Yogeshwar Kalkonde ${ }^{1}$ Sona Deshmukh ${ }^{1} \quad$ Charuta Gokhale ${ }^{1} \quad$ Mini Jacob ${ }^{2} \quad$ Abhay Bang ${ }^{1}$
}

\footnotetext{
${ }^{1}$ Society for Education, Action and Research in Community Health, Gadchiroli, Maharashtra, India

2Glenn Biggs Institute for Alzheimer's and Neurodegenerative Diseases, University of Texas Health Science Centre, San Antonio, Texas, United States
}

J Neurosci Rural Pract 2020;11:53-62
Address for correspondence Yogeshwar Kalkonde, MD, MSc, Society for Education, Action and Research in Community Health, Gadchiroli 422605, Maharashtra, India (e-mail: yvkalkonde@gmail.com).

\begin{abstract}
Background Strokes have emerged as one of the leading causes of deaths in rural India but people often remain uninformed about it. This study sought to understand knowledge, attitudes, and healthcare-seeking practices about strokes in rural Gadchiroli, India.

Methods A total of 12 focus group discussions were conducted with 34 female and 43 male participants from six villages. Responses were audio recorded, transcribed, coded, and analyzed using inductive method of qualitative data analysis.

Results Respondents correctly recognized many symptoms of stroke and were aware of the sudden onset of symptoms. They were unaware of transient ischemic attacks. After stroke, healthcare was sought from private physicians, and physicians in the government run district hospital, or traditional herbal providers depending upon the accessibility, affordability, and perceived effectiveness of the therapy. Most of the respondents thought that stroke is a serious disease associated with disability as well as death and its occurrence in the community is increasing. However, only a few participants could correctly state how stroke occurs and its risk factors. Furthermore, many participants thought that stroke cannot be prevented as it occurs suddenly without any warning.

Keywords

- stroke

- rural India

- awareness

- qualitative study

Conclusion Rural people in Gadchiroli were aware of symptoms of stroke but awareness about the etiology and the risk factors was low. Suddenness of symptoms was perceived as a key barrier to taking any preventive action. Understanding such perceptions and addressing them can help improve counseling of patients by physicians and effectiveness of behavioral change communication to prevent stroke in rural areas.
\end{abstract}

\section{Introduction}

Stroke is the second leading cause of death and disability in the world. ${ }^{1,2}$ About $75 \%$ of stroke deaths worldwide and $81 \%$ of stroke related disability now occur in low-and middleincome countries (LMICs). ${ }^{3}$ In India, the burden of disease is substantial. Fourteen percent of global disability-adjusted life years (DALYs) lost due to stroke occurs in India. ${ }^{4}$ According to the Global Burden of Disease (GBD) study, stroke was the fifth leading cause of DALYs lost in India. ${ }^{5}$ The mortality due to stroke is higher in rural India compared with urban areas. In 2015, an estimated 375,000 deaths occurred due 
to stroke in India in the premature ages between 30 and 69 years. Out of these, $71 \%$ occurred in rural India where $66 \%$ of India's population lives indicating a disproportionately higher number of deaths. ${ }^{6}$ Population-based studies have shown increasing prevalence of stroke in rural areas of India over time with prevalence of 52 to 165 per 100,000 population from 1980s to 1990s. ${ }^{7}$ Recent population-based studies from rural Gadchiroli, one of the most underdeveloped districts in India, also showed that stroke was the leading cause of death accounting for $14 \%$ of all deaths and its prevalence was high (388/100,000 population). ${ }^{8.9}$ These data indicate an urgent need to tackle the burden of stroke in rural India.

However, stroke care services in India face several challenges such as lack of awareness, financial resources, health infrastructure, and trained health personnel. ${ }^{10,11}$ Stroke awareness remains low in India. In a study conducted in a tertiary care hospital in North India, close to $25 \%$ of relatives of patients with stroke did not know any warning symptom or risk factor for stroke. ${ }^{12}$ Lack of awareness has also been shown to reduce utilization of rehabilitation services for stroke. ${ }^{13}$ Increasing awareness about stroke can improve healthcare seeking and has been shown to decrease time delay and increase thrombolysis rates in developed countries. ${ }^{14,15}$ In rural India, lack of awareness remains an important barrier to healthcare seeking for stroke. Therefore, efforts are needed to increase awareness in rural populations. To do so, gaps in the knowledge, attitudes, and practices regarding stroke need to be understood so that these can be appropriately addressed through behavioral change communication. However, such data are rare from India in general and rural India in particular. The present study aimed to understand the knowledge, attitude, and healthcare seeking practices regarding stroke in a rural community in Gadchiroli in central India, using a qualitative approach.

\section{Methods}

\section{Study Setting}

The study was conducted in a rural community of Gadchiroli district in the state of Maharashtra, India. Gadchiroli is located in central India along the eastern border of Maharashtra and has a population of approximately 1 million. It is one of the least developed districts of India, with $89 \%$ of the population living in rural areas. ${ }^{16}$ Close to $40 \%$ of the district's population is tribal. Subsistence farming and manual labor are the main occupations in the district.

There are very few qualified private medical providers in this district. The public healthcare system operated by the state government includes a district hospital, 13 rural hospitals, 45 primary health centers and 376 health subcenters. ${ }^{17}$ There is only one neurologist and one CT scanner in the entire district and treatment for acute ischemic stroke with $\mathrm{t}$-PA (tissue plasminogen activator) is not available.

\section{Study Design and Sampling}

Focus group discussions (FGDs) were conducted with participants from selected villages between August and October 2011. FGDs were conducted to gather information about (1) colloquial words used for stroke, (2) physical manifestations, (3) knowledge about the aetiology, (4) knowledge about risk factors, (5) preventive measures, (6) morbidity and mortality, (7) treatment options available in the village, (8) factors influencing access to a particular health care provider, and (9) sources of information about stroke. The FGDs were conducted separately for men and women, to allow women to express their views freely as cultural factors may inhibit women from speaking out in the presence of men.

Villages were selected from a sampling frame of 86 villages distributed in three blocks (Gadchiroli, Armori, and Chamorshi) of Gadchiroli district in the field service area of SEARCH, a non-governmental organization working in this district since 1986. Villages were chosen for FGDs if (1) the village was more than 5 kilometers away from the town of Gadchiroli and (2) had both male and female health workers of SEARCH so that they can facilitate the FGDs for males and females respectively. Out of 86 villages, 39 villages in the Gadchiroli block had both male and female community health workers (CHWs) and among these, 14 villages were more than $5 \mathrm{~km}$ from the town of Gadchiroli. Out of these 14, six villages were randomly selected with the help of a simple random table. We did not select villages within $5 \mathrm{~km}$ distance from the district hospital as people living in these villages have access to services at the district hospital or the private practitioners. The purpose of the study was to find out health seeking behavior of the larger rural community which has difficulty in accessing the services from these centers.

Participants in the selected villages were selected using purposive sampling. CHWs invited villagers to participate in the group discussions. Participants were included in the FGDs if they were (1) residents of the village for more than a year, (2) between 20 and 75 years of age, and (3) able to converse in the local language Marathi. Individuals were excluded from the FGDs if they were (1) health workers or employees of SEARCH, (2) family members of the health workers of SEARCH, (3) private or government health care providers, or (4) village heads, village council members and school teachers, as they were likely to be more informed about stroke than the rest of the villagers.

\section{Focus Group Methods}

A total of 12 FGDs were held, six each for men and women. The group discussions were conducted using a minimally structured format using an FGD guide, which was developed by a senior investigator and physician Y. K. based on clinical experience in the rural hospital of SEARCH. It was pilot tested in a village which was not a part of the study. FGDs were conducted by S.D., a physician with Master's Degree in Public Health. Recruitment for FGDs and the discussions took place in the villages. Duration of each FGD was on an average 60 minutes and discussions were assisted by the CHWs of respective villages. FGDs were audio recorded.

\section{Ethics}

This study was approved by the Institutional Ethical Committee of SEARCH. Information about the study was provided to the participants in Marathi language and verbal consent was obtained prior to the initiation of the data collection. This 
consent procedure was approved by the ethical committee. Study subjects did not receive any compensation for participation in this study.

\section{Data Analysis}

Data were analyzed using standard methods of qualitative analysis. ${ }^{18}$ All FGD and interviews were transcribed into Marathi from the digital recording. Marathi transcripts were translated into English by one author, C.G. Marathi-to-English translations were verified by another author, Y.K., to ensure that translations were accurate and nuanced meanings were not lost in translation. Investigator triangulation was used to facilitate data validation. Open coding of all transcripts was performed independently by authors Y.K., S.D., and C.G. to construct descriptive categories. The framework method of thematic analysis was used where themes were allowed to emerge from the narrative and a framework was developed to order various themes. ${ }^{19}$

\section{Results}

\section{Characteristics of the Respondents}

Seventy-seven individuals took part in FGDs-34 were women and 43 were men. Demographic profile of the participants is shown in -Table 1. Women participants had age ranging from 28 to 70 years while for men it was 25 to 73 years. Farming and manual labor were the predominant occupations. Four out of 34 women participants and 5 out of 43 men had a family member who had suffered from stroke, while 28 out of 34 women and 31 out of 43 men knew a person who had suffered from stroke.

Table 1 Demographic characteristics of the study participants

\begin{tabular}{|c|c|c|}
\hline & Women $(n=34)$ & Men $(n=43)$ \\
\hline Age & $28-70$ & $25-73$ \\
\hline \multicolumn{3}{|l|}{ Education } \\
\hline Illiterate & 20 & 12 \\
\hline 1-4th standard & 5 & 17 \\
\hline $\begin{array}{l}\text { 5-10th } \\
\text { standard }\end{array}$ & 5 & 10 \\
\hline 11-12th & 2 & 3 \\
\hline Graduate & 2 & 1 \\
\hline \multicolumn{3}{|l|}{ Occupation } \\
\hline Farming & 18 & 29 \\
\hline Manual labor & 15 & 9 \\
\hline other & 1 & 5 \\
\hline $\begin{array}{l}\text { Have a family } \\
\text { member who has } \\
\text { suffered from } \\
\text { stroke }\end{array}$ & 4 & 5 \\
\hline $\begin{array}{l}\text { Knew a person } \\
\text { who has suffered } \\
\text { from stroke }\end{array}$ & 28 & 31 \\
\hline
\end{tabular}

\section{Colloquial Words Used to Describe Stroke}

Participants were asked about the colloquial words used to describe a condition where one side of the body is suddenly paralyzed with or without involvement of same or opposite side of the face. Lakwa (paralysis), Ekkadivaat (weakness of one side of the body), and Ardhangvayu (weakness involving half of the body) were the colloquial words used to describe stroke, with Lakwa being the commonest word used.

\section{Symptoms of Stroke}

\section{Suddenness of symptoms}

When the participants were asked about the symptoms of stroke, they overwhelmingly noted the sudden appearance of symptoms. As noted by one man-

It happens very suddenly, the person feels giddy, and then his hand and leg becomes loose.

\section{Settings where stroke commonly occurred}

Participants reported that in individuals with stroke, the symptoms of stroke were noted when the affected person fell off after getting up from bed or while working. One woman recollected an event about a lady who suffered from stroke-

She went to field for work. She worked for the whole day. Then [she] went home, had dinner and slept. She fell from bed [after getting up] at night and suffered from stroke. Her one hand and leg became loose and useless. Her mouth got deviated. We admitted her [to a hospital] but she died. Thus, in stroke, hand and leg become useless and lack power, the person cannot speak.

A man summarized it as follows-

Stroke occurs suddenly. The person goes for work on his own but has to be carried by people back.

\section{Physical symptoms of stroke}

Respondents were able to correctly recognize many of the physical symptoms of stroke ( - Table 2 ).

My uncle suffered from stroke... his mouth got deviated and eye [vision] was also affected. [Male FGD participant]

Table 2 Physical symptoms associated with stroke

\begin{tabular}{|l|}
\hline Weakness of one side of the body \\
\hline Weakness in one arm \\
\hline Weakness in both legs \\
\hline Inability to walk \\
\hline Dragging feet while walking \\
\hline One eye getting small \\
\hline Deviation of mouth \\
\hline Inability to speak \\
\hline Tingling in hands \\
\hline Shaking of hands \\
\hline Shaking of head \\
\hline
\end{tabular}


Hand and leg became like [a] stick. [Male FGD participant]

The person cannot speak. Even [if] he [can] speak, one cannot understand his language. He might be asking for water and food but we do not understand and then we lose our temper on him. [Male FGD participant]

Some participants also described shaking of hands and head as a symptom of stroke.

\section{Awareness about Transient Ischemic Attacks}

The respondents were asked if they are aware of someone who had weakness or numbness in one half of body that resolved within minutes to few hours or lasted less than 24 hours. None of the respondents reported having known anyone who had such symptoms. One woman stated "Once stroke occurs, it [symptoms] cannot resolve so fast."

\section{What Causes Stroke?}

When the participants were asked about the reasons for the occurrence of stroke ( - Figure 1 ), the responses converged on following four major themes:

\section{No clear cause or destiny}

A few participants were unaware as to what caused stroke and thought that it is a 'standalone' entity without any cause. Few other participants thought that stroke occurred due to destiny or bad luck.

Stroke is stroke! It has nothing to do with other illnesses. [Female FGD participant]
Those who are destined to suffer will suffer from stroke. [Male FGD participant]

Stroke is a matter of luck. [Female FGD participant]

\section{Due to changes in food}

Stroke was thought to be caused by machine processing, adulteration, or insecticide treatment of the food by several participants.

In our childhood, hand pounded rice was used but nowadays machine polished rice is used which does not have vitamins. Because of this, all types of illnesses have increased so obviously stroke has also increased. [Male FGD participant]

The food habits have changed. Now everything is readymade and prepacked. In older times, jawas [flax seed] was produced in farm and its oil [processed at home] was used for cooking. Now, we buy oil from market which has higher chances of adulteration. This may cause stroke. [Male FGD participant]

Now people use chemicals in farming as against compost manure in olden days. Everything [that we eat] has chemicals which results increase in stroke. [Male FGD participant]

Explanations based on Ayurveda, the traditional Indian system of medicine, and local beliefs about health Some respondents associated occurrence of stroke with increase in the humor Vata as described in Ayurveda. Vata humor in Ayurveda is associated with air, and weakness in

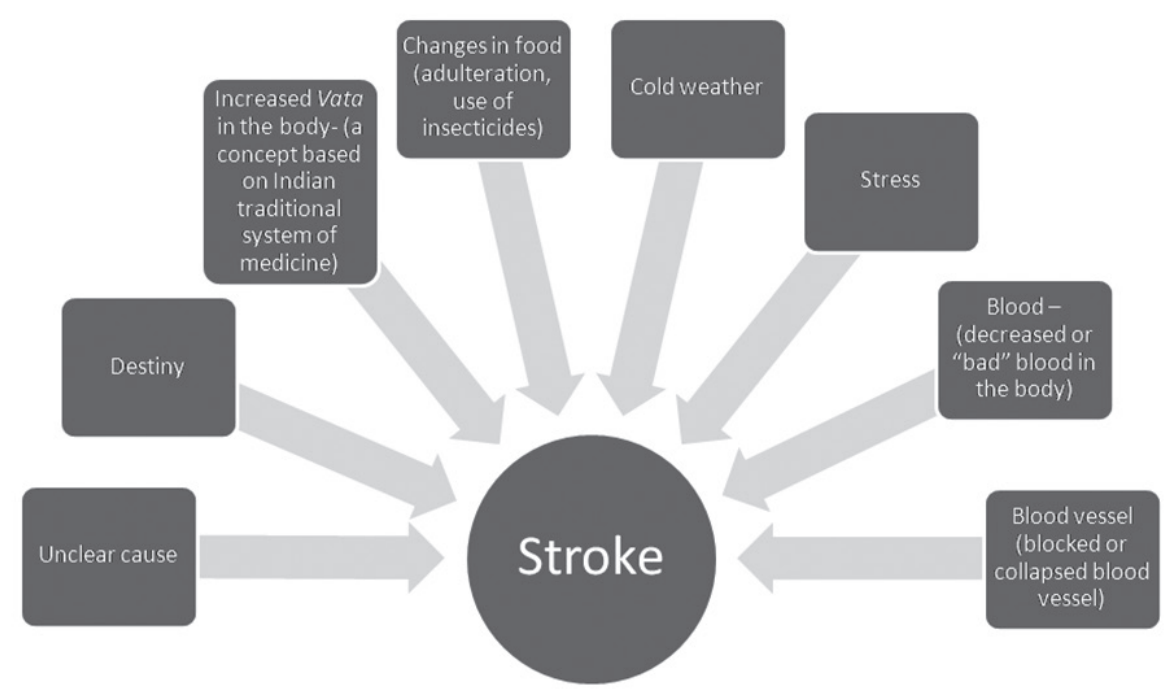

Fig. 1 People's perceptions about the causes of stroke. 
limbs is attributed to increase in air or lightness in that body part.

If the person is strong and has ample of blood [in his body] then his health remains good but if he develops weakness then stroke may happen as the Vata increase in the person's body. [Female FGD participant]

The respondents invoked the concept of Vata and often combined it with other factors such as weather to explain occurrence of stroke.

It happens due to cold weather. Due to cold weather, Vata is produced [in the body] and this may result in stroke. [Female FGD participant]

It may happen due to cold [weather]. My father used to bathe buffalos in cold water so he may have suffered from stroke. [Male FGD participant]

Other responds associated occurrence of stroke with sprain involving the whole body.

Strenuous physical work can cause sprain in the [whole] body and that sprain may give rise to stroke. [Male FGD participant]

\section{Explanations that come close to the scientific} understanding of stroke

Some participants thought that stroke is a disorder of blood, occurring due to deficiency of blood or 'bad' blood.

It [stroke] is a disease of blood. As the blood decreases in body, weakness occurs and due to weakness, stroke occurs. [Female FGD participant]

Stoke is a disorder of blood. Blood becomes bad. [Female FGD participant]

A few participants came close to associating stroke with reduced blood supply but often incorrectly associated it with reduced blood supply to the affected part of the body and not brain.

When the blood flow stops then stoke occurs. The vessel comes from brain so if the vessel in hand gets closed then hand gets affected by stroke. [Female FGD participant]

If blood circulation to a particular part of body is reduced then that particular part cannot work means the cause of stroke is reduced blood circulation of that part of body. [Male FGD participant]

Very few participants were aware that it occurred due to closure of a blood vessel supplying brain or reduced blood supply to brain.

I think it is a disease of the brain. Sometime due to weakness, the vessels get closed. I think the brain [blood] vessel gets closed. [Male FGD participant]

One of the participants whose daughter died of stroke had correct information regarding the causation of stroke:

... lack of blood supply to brain results in stroke.

\section{Risk Factors for Stroke}

Participants were unable to list factors that increase the risk of stroke and often mixed diseases etiology with the risk factors. We therefore, probed participants regarding association of known risk factors with occurrence of stroke. Only a few participants were aware of the risk factors and among them the opinion about whether a given risk factor is related to stroke was divided ( - Table $\mathbf{3}$ ).

Emotional stress was listed as a risk factor by one respondent.

If someone has sudden tension [stress] in life, like if somebody is forced to do what he does not want to do then tension [stress] will always be in his mind. So if this tension [stress] persists it will bring weakness to the person's body and this may result in stroke. [Male FGD participant]

\section{Perception about Stroke as a Serious Disease}

Almost all the respondents thought that stroke is a serious disease due to high risk of death and disability.

\section{[Many] people die from stroke. [Female FGD participant]}

Some [stroke patients] manage [to survive] but remain in their wretched state for 5 to10 years. [Male FGD participant]

After stroke, the body is rendered useless. For everything, the person has to depend on his family-bathing, eating etc. Then what that person does is that he gets tired by this and so he leaves food and prays for early death. [Male FGD participant]

Respondents also felt that stroke can cause significant burden on family members.

Whole family gets disturbed. If the earning male of a family suffers from stroke then the wife's life becomes hell. She may have to earn the bread by working as a laborer in forest (a common local occupation). She will [spend on] treat [ment] as much as she can afford. She will take suggestions from other people for treatment. So she will do as much treatment as possible but after a limit, she will let her husband die. [Female FGD participant]

The person becomes handicapped. He cannot work. His body does not work, then [his] children also say that let that old man die. [Male FGD participant]

\section{Perceptions about Recovery from Stroke}

Most of the respondents thought that those who suffer from stroke can recover fully or partially if the patient is young, has only one extremity involved, or if the treatment is sought early.

If stroke occurs in young age, then there are chances for complete recovery. [Male FGD participant]

If only one hand or one leg is affected, then there are chances that the person will recover. [Female FGD participant] 
Table 3 Knowledge and perceptions favoring and opposing association of stroke with the established risk factors of stroke

\begin{tabular}{|c|c|c|}
\hline Risk factor & Those favoring association & Those opposing an association \\
\hline Hypertension & $\begin{array}{l}\text { Stroke occurs due to [high] blood pressure. [Widow of } \\
\text { a person who died due to stroke] } \\
\text { When B.P. [blood pressure] increases it will result in } \\
\text { rupture of blood vessel [in the brain] so the person will } \\
\text { suffer from stroke. [Male FGD participant] } \\
\text { Doctors say that sudden rise in B.P. can cause stroke. } \\
\text { [A traditional healer] }\end{array}$ & $\begin{array}{l}\text { I have seen B.P. [hypertensive] patients dying but } \\
\text { have not seen them suffering from stroke. }\end{array}$ \\
\hline Diabetes & $\begin{array}{l}\text { Yes, I think there is relationship. Diabetes produces } \\
\text { weakness in body and this weakness may cause stroke. } \\
\text { I am very sure about it. [Male FGD participant] } \\
\text { Yes, it is related to stroke. Danger of stroke increases } \\
\text { with diabetes. [Female FGD participant] }\end{array}$ & $\begin{array}{l}\text { Stroke happens suddenly while diabetes is a long } \\
\text {-term disease and one [the person who has diabe- } \\
\text { tes] is not aware if he is suffering from this disease. } \\
\text { So these two cannot be related. [Female FGD } \\
\text { participant] }\end{array}$ \\
\hline $\begin{array}{l}\text { Ischemic heart } \\
\text { disease }\end{array}$ & $\begin{array}{l}\text { If the person has heart attack he will fall down. Simi- } \\
\text { larly, the person with stroke can also fall down so they } \\
\text { might be related. [Female FGD participant] }\end{array}$ & $\begin{array}{l}\text { No, they are two different diseases. [Male FGD } \\
\text { participant] }\end{array}$ \\
\hline Obesity & $\begin{array}{l}\text { Yes, It is related. As my neighbor is obese and he is } \\
\text { suffering from stroke, so it may be related. [Male FGD } \\
\text { participant] } \\
\text { It happens definitely more in obese people as they have } \\
\text { higher amount of fat in their blood. Because of fat, the } \\
\text { blood vessel gets narrowed and blood circulation reduc- } \\
\text { es. So obese person suffers from stroke. [Female FGD } \\
\text { participant] }\end{array}$ & $\begin{array}{l}\text { Stroke occurs in fat as well as thin person so } \\
\text { being fat cannot be related to stroke. [Male FGD } \\
\text { participant] }\end{array}$ \\
\hline Tobacco & $\begin{array}{l}\text { Some people eat gutka [a smokeless tobacco product] } \\
\text {... that might cause stroke. [Female FGD participant] } \\
\text { Tobacco causes intoxication so it may be related to } \\
\text { stroke. [Male FGD participant] }\end{array}$ & $\begin{array}{l}\text { Consumption of tobacco leads to cancer and ulcer } \\
\text { and [it] has nothing to do with stroke. [Male FGD } \\
\text { participant] } \\
\text { Whole world eats tobacco but we have not seen } \\
\text { anybody suffering from stroke due to tobacco. } \\
\text { [Female FGD participant] } \\
\text { [Smoking tobacco] causes TB [and not stroke]. } \\
\text { Person dies by coughing. [Female FGD participant] }\end{array}$ \\
\hline Alcohol & $\begin{array}{l}\text { In Moha liquor [ liquor made locally from flowers of } \\
\text { Mahua tree] the flowers are kept for decomposition } \\
\text { in plastic containers...the chance of stroke increase by } \\
\text { consumption of such liquor. [Female FGD participant] } \\
\text { Nowadays alcohol is drinking the man. The blood } \\
\text { cells get damaged. These blood cells then lack power } \\
\text { in them and this weakness cause stroke. [Male FGD } \\
\text { participant] }\end{array}$ & $\begin{array}{l}\text { Nothing happens to those drinking alcohol. Mr. } \\
\text { [ABC] never used drinks. Mr. [XYZ] never used to } \\
\text { drink but still they suffered from stroke. [Female } \\
\text { FGD participant] }\end{array}$ \\
\hline Heredity & $\begin{array}{l}\text { Elders used to say that stroke comes via generations. If } \\
\text { our grandfather or great grandfather has suffered from } \\
\text { stroke then its partial effect can come in the present } \\
\text { generation. [Male FGD participant] }\end{array}$ & \\
\hline
\end{tabular}

Abbreviations: TB, tuberculosis; FGD, focus group discussion

If it is the beginning of stroke and treatment is done properly, then the person may recover completely but still he cannot resume his normal work as before. Some weakness does remain in body. [Female FGD participant]

One of the women respondents noted that stroke is incurable-" This is not a disease which can be cured."

\section{Perceptions about the Occurrence of Stroke in the Community}

Several participants thought that the occurrence of stroke in the community is on the rise and a few respondents attributed it to the use of machine processed food.
In old times, there were not many patients with stroke, nowadays the illness has increased. [Male traditional healer]

Because we are eating food processed from machines, so the proportion of disease has increased. [Female FGD participant]

However, a few respondents felt that the prevalence of stroke in the community has reduced due to availability of medical care. One male respondent reported-"[Occurrence] was high in older times but now as there are many doctors available, so the occurrence of the disease has reduced." 
The prevalence of stroke was thought to be more in older age compared with those who are younger. However, a few participants felt that stroke among young is on the rise as noted by a man-“... nowadays the young generation from 15 to 18 years [of age] suffers from stroke."

The prevalence of stroke was thought to be more among men; however, a few respondents thought that it was equal among both sexes.

\section{Prevention of Stroke}

When the respondents were asked if stroke can be prevented, some respondents believed that it is not possible to prevent stroke as it occurs suddenly without any warning.

The disease, stroke, happens suddenly so it cannot be prevented but treatment can be done. [Female FGD participant]

We cannot predict whether we are going to suffer from stroke then how can we prevent it? [Male FGD participant]

We do not know what causes stroke. Then, how can we take the precautions to prevent stroke? [Female FGD participant]

However, a few respondents thought that dietary modification, exercise, quitting tobacco and alcohol, and Yoga can help prevent stroke.

No salt, spicy food. No sour food. One should only eat plain rice and lentil soup. No potato or beans in food as they are cold natured food and these kinds of food should be avoided. [Female FGD participant]

Alcohol, kharra, and gutka [locally used smokeless tobacco products]; all these cause weakness in vessels. So if we can keep our self away from the addictions and maintain healthy body then stroke can be prevented. [Male FGD participant]

It can be prevented by going for morning walk as morning walk increases pure oxygen in the body; this oxygen will improve the blood supply in the body. Along with walk, one should also do pranayama [a yogic breathing exercise] as it has been stated that pranayama removes most dangerous nontreatable diseases [from body]. [Male FGD participant]

A few respondents thought that stroke can be prevented by medical checkups and taking appropriate medicines.

If we go to doctor and get ourselves examined and take certain medicine then stroke can be prevented.

[Male FGD participant]

If it is diagnosed [early] then it can be prevented. [Female FGD participant]

\section{Health Care Seeking for Stroke}

Most of the participants agreed that if someone develops stroke, family will seek care.
Even poorest of the poor will try to get some treatment for family member suffering from stroke. [Female FGD participant]

Healthcare was sought from three major sources-private physicians, district hospital of the government health services, and traditional herbal providers.

First, we go to a private doctor in village, then we seek care at government or private doctor [at the district headquarter]. And then finally, will seek traditional herbal care. If [the symptoms are] still not relieved then will let the person die. [Female FGD participant]

Affordability of healthcare and response to treatment determined the provider from whom the treatment was sought.

If the person is poor, he will seek care at a government hospital. If rich, then he will go to private practitioner. [Female FGD participant]

Those whose illness was reduced by seeking hospital treatment will have faith over hospital treatment similarly those whose illness recovered due to traditional herbal medicine will have faith on traditional medicine. [Female FGD participant]

\section{Source of Information about Stroke}

The respondents learned about stroke from family members, community members who suffered from stroke, and from physicians.

My husband suffered from stroke. He and other two family members also suffered from stroke. So, I know. [Female FGD participant]

People talk that, so and so has suffered from stroke. This kind of discussion sometimes gives information. [Male FGD participant]

Doctors tell this kind of information when I go for my BP [blood pressure] check-up.[Male FGD participant]

\section{Discussion}

To our knowledge, this is the first community-based qualitative study about knowledge, attitudes, and healthcare-seeking practices for stroke from rural India. Study participants from this rural community of farmers and manual laborers in one of the most underdeveloped districts in India, were familiar with the symptoms of stroke. A majority knew a stroke patient and thought that the occurrence of stroke was on the rise. The little correct knowledge that the participants had, was attributed to personal experiences with stroke patients or interaction with doctors during healthcare visits. Despite their awareness of stroke as a serious disease and its consequences, people were not aware of the risk factors for stroke and many thought that it is difficult to prevent stroke as it occurred suddenly. This could be significant barrier to stroke prevention. Our study highlights an urgent need to 
increase awareness about stroke in rural India and provides important insights to develop material for behavioral change communication.

Research from India regarding knowledge about stroke has mostly been from hospital-based quantitative studies and limited to urban areas. In an urban hospital-based study in the city of Ludhiana in India, $77 \%$ of the relatives of patients without stroke knew at least one symptom of stroke and $79 \%$ knew at least one risk factor. ${ }^{12}$ In another hospital based study in Burdwan, in the state of West Bengal in India, interviewed stroke patients as well as persons who accompanied them, had a much lower levels of awareness. Only a quarter of both groups were aware of hypertension as a risk factor or unilateral weakness as a symptom. ${ }^{20}$ In a community-based study in the city of Kolkata in West Bengal in India, awareness levels were high, with $87 \%$ of individuals from families nonaffected by stroke and $92 \%$ of individuals from stroke-affected families being aware of paralysis of half of the body as a symptom and approximately $83 \%$ of both groups aware that hypertension was a risk factor. ${ }^{21}$ Findings from these studies suggest that there are considerable regional variations in knowledge about stroke in India. Since all these studies were from urban areas; it is likely that rural areas, with lower education levels and lack of access to information regarding stroke may have even lower awareness levels. In fact, unpublished data from one of our studies among stroke survivors in Gadchiroli has shown that awareness regarding risk factors to be very low. The present qualitative study among community members in Gadchiroli provides important and rich insights regarding community perceptions that are not available from previously published studies from India.

Qualitative studies regarding perceptions of people regarding stroke are rare in the published literature. ${ }^{22-27}$ There are few studies from stroke survivors from rural Indonesia where the investigators explored the understanding of stroke patients regarding the diseases and how stroke altered their life. ${ }^{23-25}$ We compared our findings with those from these studies. Patients in a study from Indonesia thought that stroke is a temporary and curable disorder. ${ }^{25}$ In contrast, the participants in our study seemed to have a more nuanced perceptions about recovery after stroke. They thought that a patient with stroke can recover if the patient is young, if only one extremity is affected and if treatment is sought early. In terms of factors leading to stroke, none of the participants from the study in Indonesia or our study ascribed stroke to demons and witchcraft, which was the case in qualitative studies done in Africa. ${ }^{22,26,27}$ The reason for this difference could include higher access to information in our study population, lack of religious-cultural explanatory models of stroke due to alternative explanations in the Indian traditional system of Ayurveda and an effect of time as the studies from Africa were conducted more than 10 years before the current study. Stroke was linked to abnormality in the blood vessels in a study from Indonesia and few participants in our study also thought that stroke occurred because of abnormality in blood vessels. ${ }^{23}$ One of the participants in our study who reported this association had a daughter who died due to stroke, indicating knowledge acquisition through
Table 4 Potential strategies for behavioral change communication in rural areas based on the observations in the study

\begin{tabular}{|l|l|}
\hline Observations & Potential strategy \\
\hline $\begin{array}{l}\text { Some acceptance } \\
\text { of the biomedical } \\
\text { model of stroke }\end{array}$ & $\begin{array}{l}\text { This acceptance of biomedical model } \\
\text { can be leveraged to provide informa- } \\
\text { tion about stroke and its risk factors. }\end{array}$ \\
\hline $\begin{array}{l}\text { Some participants } \\
\text { were aware about } \\
\text { the risk factors for } \\
\text { stroke }\end{array}$ & $\begin{array}{l}\text { Association of stroke risk factors with } \\
\text { other chronic diseases e.g., ischemic } \\
\text { heart disease and cancer can be high- } \\
\text { lighted to stress the broader benefits } \\
\text { of preventive measures for stroke. }\end{array}$ \\
\hline $\begin{array}{l}\text { Perceived role } \\
\text { of food in the } \\
\text { causation of } \\
\text { stroke }\end{array}$ & $\begin{array}{l}\text { This perception can be used to } \\
\text { promote diet that reduces cardiovas- } \\
\text { cular risk e.g., inclusion of fruits and } \\
\text { vegetables in diet and reducing salt } \\
\text { consumption. }\end{array}$ \\
\hline $\begin{array}{l}\text { Acceptance of } \\
\text { yoga and other } \\
\text { exercises as pre- } \\
\text { ventive measures } \\
\text { for stroke by some } \\
\text { participants }\end{array}$ & $\begin{array}{l}\text { Promoting physical exercises along } \\
\text { with yoga to prevent stroke. }\end{array}$ \\
\hline $\begin{array}{l}\text { Perceptions that } \\
\text { run contrary to } \\
\text { association of } \\
\text { known risk factors } \\
\text { with stroke }\end{array}$ & $\begin{array}{l}\text { Need to be specifically addressed } \\
\text { while providing health messag- } \\
\text { es. The concept of risk instead of } \\
\text { all-or-none-association of risk factors } \\
\text { with stroke needs to be explained. }\end{array}$ \\
\hline $\begin{array}{l}\text { Perception that } \\
\text { stroke cannot be } \\
\text { prevented due to } \\
\text { acute onset where } \\
\text { there is no time } \\
\text { to take preventive } \\
\text { action }\end{array}$ & $\begin{array}{l}\text { Conveying that it is too late to prevent } \\
\text { stroke once the symptoms have } \\
\text { developed. Highlighting the need to } \\
\text { take preventive action so that stroke } \\
\text { (symptoms) do not develop. }\end{array}$ \\
\hline $\begin{array}{l}\text { Low awareness } \\
\text { about TIA }\end{array}$ & $\begin{array}{l}\text { Information about TIAs should be } \\
\text { specifically provided during BCC. }\end{array}$ \\
\hline Abtevions: Tis,
\end{tabular}

Abbreviations: TIAs, transient ischemic attacks; BCC, behavioral change communication.

a lived experience. Among risk factors, stress, hypertension, and oily foods were linked to the risk of stroke in a study from Tanzania. ${ }^{22}$ In our study too, participants linked stress, hypertension, and insecticide treated or machine processed food with the risk of stroke. In addition, a few patients in our study could also state diabetes, ischemic heart disease, use of alcohol and tobacco, and hereditary factors as the risk factors for stroke.

Somewhat encouraging finding from our study was that many of the participants could recognize symptoms of stroke correctly, probably through experiential knowledge as many had known someone who had stroke. However, it was concerning that awareness about risk factors for stroke was poor and some participants had perceptions which countered the association of known risk factors with stroke. Most of the respondents were unaware of symptoms of TIA.

Information about people's knowledge, attitudes, and practices regarding stroke would be important for the development of behavioral change communication (BCC) campaigns for prevention of stroke, particularly in rural areas. 
Such campaigns should contain key messages that enable individuals to actively make choices that reduce risk and respond appropriately to early warning signs. Findings of this study can be used to design strategies for BCC campaigns for stroke ( - Table 4). First, this rural community demonstrates awareness about some parts of the biomedical model of disease while retaining belief in ethnomedicine, specifically the naturalistic system on which Ayurveda is based. The mixture of explanatory theories sourced from modern medicine as well as traditional beliefs passed on by older family members indicate that a message based on the biomedical model may be acceptable to the community. Second, participants from this study already suspected change in the food as an important risk factor for stroke. This belief can be used to provide information regarding appropriate foods which need to be consumed to prevent stroke such as reducing salt consumption and increasing intake of fruits and vegetables. ${ }^{28}$ Third, existing socio-cultural beliefs, traditions, and perceptions which counter association of stroke with known risk factors will have to be addressed during BCC. For example, some participants countered the association between hypertension, obesity, and tobacco use with stroke stating that those without these conditions also had stroke, so for them these associations seemed illogical. These perceptions highlight a need to explain the concept of risk rather than an all-or-none type association between the risk factors and stroke. Fourth, due to acute onset of symptoms, people thought that there is no time to take preventive action for stroke once the symptoms developed. To address this perception, the messages regarding prevention need to be reframed. It needs to be highlighted that it is too late to take a preventive action once the symptoms have developed but steps can be taken to reduce the risk so that the symptoms of stroke do not develop. The sequence of events in the body which lead to stroke needs to be explained in simple terms for rural societies in India. Fifth, the awareness about TIA also needs to be increased. Sixth, as the risk factors of stroke are shared with many chronic diseases and the prevalence of such risk factors is on the rise in rural India, highlighting that stroke preventive measures could bring in additional benefit of preventing other chronic diseases such as ischemic heart disease, chronic kidney diseases and cancers would be important.

However, it needs to be acknowledged that education alone may not lead to changes in stroke care in rural communities in India. In rural communities, individual choices that are made regarding treatment are engineered by multiple social conditions beyond a mere lack of awareness. Unreliable primary health care, distances to tertiary care centers, poor transport facilities, and prohibitive cost of stroke care at the tertiary level (even within the public healthcare system) prove to be too large a barrier for impoverished populations in receiving acute care as well as preventive treatments for stroke. ${ }^{10}$ It is expected that over time, with expanding implementation of the National Program for Prevention and Control of Cancer, Diabetes, Cardiovascular Diseases and Stroke (NPCDCS), one of the largest programs in the world to tackle the burden of chronic noncommunicable diseases, there will be greater access to preventive care of stroke in rural populations in India. ${ }^{29}$ Insights from our study would be potentially useful for designing health awareness material for stroke in the NPCDCS program and can promote care seeking for stroke prevention.

The study has several strengths. It was a community-based study from a well-defined population in rural India. We conducted FGDs separately for women so that they could express themselves freely. We also included participants from various age groups and educational levels. There are also some limitations. As our study was limited to FGDs among community members, it was not possible to explore complex beliefs of individuals in depth. Also, we did not interview patients with stroke. Such patients could have had more knowledge about stroke and its risk factors and the difficulties faced by them could be highlighted. However, participants in this study could enlist many difficulties faced by patients with stroke as many of them had seen or had a relative with stroke. Also, as the study was conducted by the staff of SEARCH who have worked in the area, it is possible that study participants were biased toward a biomedical model of disease causation and hesitated to express more traditional views. On the other hand, familiarity with the staff could also have promoted community engagement in the study and open communication. One more limitation of the study is that the findings are being reported after 8 years of conducting the study. However, in absence of any formal health awareness program in rural areas of India, the knowledge, perceptions, or practices regarding stroke are unlikely to have changed significantly which is corroborated by our current clinical experience in a busy rural hospital in this area. Therefore, the findings of the study continue to be very relevant.

\section{Conclusion}

Our study shows that this rural community in Gadchiroli was aware of stroke symptoms and thought that the occurrence of stroke is increasing. However, people had limited knowledge about the etiology and the risk factors of stroke and many thought that stroke would be hard to prevent as it occurs suddenly without any warning. There were also perceptions which countered the association of known risk factors with stroke. Our study provides important insights from a rural community which can help design culturally appropriate health awareness material for behavioral change to improve stroke care in rural areas.

\section{Funding}

SEARCH was supported by the John D. and Catherine T. MacArthur Foundation.

\section{Authors' Contributions}

Conceived and designed the study (Y.K.), data collection (S.D.), analysis (S.D., Y.K., and C.G.), drafted the manuscript (Y.K., M.J.), revised the manuscript draft critically for important intellectual content (Y.K., M.J., and A.B.). 


\section{Conflict of Interest}

None declared.

\section{Acknowledgment}

The authors thank Ms. Sweta Roy, Ms. Sindhu Nila, field supervisors, and community health workers of SEARCH for their assistance during the study. They also thank all the study participants for their time and cooperation during the study.

\section{References}

1 GBD 2016 DALYs and HALE Collaborators. Global, regional, and national disability-adjusted life-years (DALYs) for 333 diseases and injuries and healthy life expectancy (HALE) for 195 countries and territories, 1990-2016: a systematic analysis for the Global Burden of Disease Study 2016. Lancet 2017;390(10100):1260-1344

2 GBD 2016 Causes of Death Collaborators. Global, regional, and national age-sex specific mortality for 264 causes of death, 1980-2016: a systematic analysis for the Global Burden of Disease Study 2016. Lancet 2017;390(10100):1151-1210

3 Feigin VL, Krishnamurthi RV, Parmar P, et al. GBD 2013 Writing Group; GBD 2013 Stroke Panel Experts Group. Update on the Global Burden of Ischemic and Hemorrhagic Stroke in 1990-2013: The GBD 2013 Study. Neuroepidemiology 2015;45(3):161-176

4 India State-Level Disease Burden Initiative CVD Collaborators. The changing patterns of cardiovascular diseases and their risk factors in the states of India: the Global Burden of Disease Study 1990-2016. Lancet Glob Health 2018;6(12):e1339-e1351

5 India State-Level Disease Burden Initiative Collaborators. Nations within a nation: variations in epidemiological transition across the states of India, 1990-2016 in the Global Burden of Disease Study. Lancet 2017;390(10111):2437-2460

6 Ke C, Gupta R, Xavier D, et al. Million Death Study Collaborators. Divergent trends in ischaemic heart disease and stroke mortality in India from 2000 to 2015: a nationally representative mortality study. Lancet Glob Health 2018;6(8):e914-e923

7 Gourie-Devi M. Epidemiology of neurological disorders in India: review of background, prevalence and incidence of epilepsy, stroke, Parkinson's disease and tremors. Neurol India 2014;62(6):588-598

8 Kalkonde YV, Deshmukh MD, Sahane V, et al. Stroke is the leading cause of death in rural Gadchiroli, India: a prospective community-based study. Stroke 2015;46(7):1764-1768

9 Kalkonde YV, Sahane V, Deshmukh MD, Nila S, Mandava P, Bang A. High prevalence of stroke in rural Gadchiroli, India: a community-based study. Neuroepidemiology 2016;46(4):235-239

10 Pandian JD, Sudhan P. Stroke epidemiology and stroke care services in India. J Stroke 2013;15(3):128-134

11 Pandian JD, William AG, Kate MP, et al. Strategies to improve stroke care services in low- and middle-income countries: a systematic review. Neuroepidemiology 2017;49(1-2):45-61

12 Pandian JD, Jaison A, Deepak SS, et al. Public awareness of warning symptoms, risk factors, and treatment of stroke in northwest India. Stroke 2005;36(3):644-648
13 Mahak C, Shashi, Yashomati, et al. Assessment of utilization of rehabilitation services among stroke survivors. J Neurosci Rural Pract 2018;9(4):461-467

14 Alberts MJ, Perry A, Dawson DV, Bertels C. Effects of public and professional education on reducing the delay in presentation and referral of stroke patients. Stroke 1992;23(3):352-356

15 Morgenstern LB, Staub L, Chan W, et al. Improving delivery of acute stroke therapy: the TLL Temple Foundation Stroke Project. Stroke 2002;33(1):160-166

16 Demography | District Gadchiroli, Government of Maharashtra [Internet]. Available at: https://gadchiroli.gov.in/demography. Accessed May 27, 2019

17 District at A Glance | District Gadchiroli, Government of Maharashtra [Internet]. Available at: https://gadchiroli.gov.in/ district-at-a-glance. Accessed May 27, 2019

18 Patton M. Qualitative Evaluation and Research Methods. Thousand Oaks CA, United States: Sage Publications; 1990:536

19 Gale NK, Heath G, Cameron E, Rashid S, Redwood S. Using the framework method for the analysis of qualitative data in multi-disciplinary health research. BMC Med Res Methodol 2013;13:117

20 Das K, Mondal GP, Dutta AK, Mukherjee B, Mukherjee BB. Awareness of warning symptoms and risk factors of stroke in the general population and in survivors stroke. J Clin Neurosci 2007; 14(1):12-16

21 Das S, Hazra A, Ray BK, et al. Knowledge, attitude, and practice in relation to stroke: a community-based study from Kolkata, West Bengal, India. Ann Indian Acad Neurol 2016;19(2):221-227

22 Mshana G, Hampshire K, Panter-Brick C. Walker R. Urban-rural contrasts in explanatory models and treatment-seeking behaviours for stroke in Tanzania.J Biosoc Sci 2008;40(1):35-52

23 Norris M, Allotey P, Barrett G. "I feel like half my body is clogged up": lay models of stroke in Central Aceh, Indonesia. Soc Sci Med 2010;71(9):1576-1583

24 Norris M, Allotey P, Barrett G. Nonbiomedical stroke practitioners in Aceh. Int J Stroke 2011;6(2):152-154

25 Norris M, Allotey P, Barrett G. 'It burdens me': the impact of stroke in central Aceh, Indonesia. Sociol Health Illn 2012;34(6):826-840

26 Hundt GL, Stuttaford M, Ngoma B; SASPI Team. The social diagnostics of stroke-like symptoms: healers, doctors and prophets in Agincourt, Limpopo Province, South Africa. J Biosoc Sci 2004;36(4):433-443

27 Bham Z, Ross E. Traditional and western medicine: cultural beliefs and practices of South African Indian Muslims with regard to stroke. Ethn Dis 2005;15(4):548-554

28 O'Donnell MJ, Chin SL, Rangarajan S, et al. INTERSTROKE investigators. Global and regional effects of potentially modifiable risk factors associated with acute stroke in 32 countries (INTERSTROKE): a case-control study. Lancet 2016;388(10046):761-775

29 National Program for Prevention and Control of Cancer. Diabetes, CVD and Stroke(NPCDCS) | National Health Portal Of India [Internet]. Available at: https://www.nhp.gov.in/national-programmefor-prevention-and-control-of-c_pg. Accessed May 27, 2019 